\title{
Eventos de Precipitação Extrema na Região do Centro de Lançamento de Alcântara
}

\author{
Marcos Daisuke Oyama ${ }^{1}$, Gabriel Miller de Oliveira ${ }^{2}$ \\ ${ }^{1}$ Instituto de Aeronáutica e Espaço, São José dos Campos, SP, Brasil. \\ ${ }^{2}$ Universidade Federal de Itajubá, Itajubá, $M G$, Brasil.
}

Recebido: 9/12/2015 - Aceito: 27/4/2016

\begin{abstract}
Resumo
Totais diários de precipitação foram utilizados para identificar os eventos de Precipitação Extrema (PE) na região do Centro de Lançamento de Alcântara (CLA) para o período de set-1984 a ago-2014 (30 anos). Adotando o $99^{\circ}$ percentil dos totais diários $\left(44 \mathrm{~mm} \mathrm{~d}^{-1}\right.$ ) como limiar de PE, foram identificados 104 eventos no período. O ciclo anual da frequência de eventos e das excedências foi muito semelhante ao ciclo anual da precipitação, com máximo (mínimo) no trimestre MAM (SON). Utilizando as séries de duração parcial, os máximos anuais de total diário (definindo ano hidrológico como os 12 meses a partir de setembro) puderam ser modelados estatisticamente como uma distribuição de Gumbel. A precipitação de 1 dia com tempo de retorno de 100 anos seria de $115 \mathrm{~mm}$, valor inferior aos encontrados na literatura para localidades pertencentes à região do CLA. Para o bimestre de março e abril, que concentrou a maior frequência de eventos, a variabilidade interanual da frequência esteve correlacionada positiva e significativamente $(R=+0,44)$ com o total de precipitação, e a correlação parcial com outros fatores (índice Niño 3, gradiente interhemisférico de temperatura da superfície do mar do Atlântico e vento em $925 \mathrm{hPa}$ sobre a região do CLA) não foi significativa. Os dias de PE no bimestre diferenciaram-se dos demais com totais elevados por apresentarem maior número de horas do dia com chuva $\left(14 \pm 4 \mathrm{~h}\right.$ ) e maiores totais horários (p. ex., total horário máximo $=23 \pm 9 \mathrm{~mm} \mathrm{~h}^{-1}$ ). No bimestre de março e abril de 1996, quando houve a maior frequência de eventos (5 eventos), os dias de PE caracterizaram-se pela ocorrência de atividade convectiva intensa sobre duas grandes áreas: uma zonalmente alongada cobrindo a costa norte do Brasil, e outra cobrindo os Estados de Santa Catarina e Paraná.
\end{abstract}

Palavras-chave: costa norte do Brasil, dias de precipitação intensa, Meteorologia Aeroespacial.

\section{Extreme Precipitation Events in the Alcântara Launch Center Region}

\begin{abstract}
Daily precipitation data were used to identify the Extreme Precipitation (EP) events in the Alcântara Launch Center (Centro de Lançamento de Alcântara, CLA) region for the period from Sept-1984 to Aug-2014 (30 years). Selecting the $99^{\text {th }}$ percentile $\left(44 \mathrm{~mm} \mathrm{~d}^{-1}\right)$ as the threshold for EP, 104 events were identified in the period. The annual cycle of the EP events frequency and exceedances was similar to the annual cycle of precipitation, with maxima (minima) in the MAM (SON) quarter. Using the peaks-over-threshold approach, the annual maximum daily precipitation (defining hydrological year as 12 months from September) could be statistically modeled as a Gumbel distribution. The 1-day precipitation with return period of 100 years would be $115 \mathrm{~mm}$, which is lower than the values found in the literature for localities within the CLA region. For the March and April bimester, when the largest frequency of events occurred, the interannual variability of the frequency was correlated positively and significantly $(R=+0.44)$ with the total precipitation, and the partial correlation with other factors (such as Niño 3 index, interhemispheric sea surface temperature gradient in the Atlantic and wind at $925 \mathrm{hPa}$ over the CLA region) was not significant. In the bimester, the EP days differed from the others with high totals as they showed greater number of hours with rain $(14 \pm 4 \mathrm{~h})$ and greater hourly totals $(e . g$., maximum hourly precipitation $=23 \pm 9 \mathrm{~mm} \mathrm{~h}^{-1}$ ). In the bimester of a specific year, 1996, when the highest frequency of events (5 events) was found, the EP days were characterized by an intense convective activity over two large areas: one zonally oriented covering the northern coast of Brazil, and the other covering the States of Santa Catarina and Paraná.
\end{abstract}

Keywords: northern coast of Brazil, heavy precipitation days, Aerospace Meteorology.

Autor de correspondência: Marcos Daisuke Oyama, marcos.oyama@ymail.com. 


\section{Introdução}

No Centro de Lançamento de Alcântara (CLA; Fig. 1), localizado no litoral do Maranhão, realiza-se o lançamento de foguetes projetados e construídos no Instituto de Aeronáutica e Espaço (IAE). O lançamento de foguetes requer informações de elementos meteorológicos visando à segurança do vôo (Marques e Fisch, 2005). Os aspectos climatológicos do local, particularmente relacionados ao vento e à ocorrência de precipitação e descargas atmosféricas, determinam os períodos favoráveis aos lançamentos e às atividades espaciais no CLA.

No presente trabalho, abordam-se os eventos de Precipitação Extrema (PE). Embora precipitação de qualquer intensidade restrinja as atividades e operações em foguetes não-impermeáveis, os eventos de PE podem levar a restrições ainda maiores, além do potencial de impactos socioeconômicos consideráveis não somente para o CLA, mas também para as localidades no seu entorno (como as cidades mostradas na Fig. 1). Assim, o trabalho possui o objetivo geral de caracterizar os eventos de PE na região do CLA.

Existe uma extensa literatura sobre os eventos de PE (p. ex., Easterling et al., 2000; Dayan et al., 2015). Para o Brasil, há trabalhos que enfocam o país ou a América do Sul (p. ex., Grimm e Tedeschi, 2009; Gonçalves, 2011), ou regiões (ou localidades) específicas (p. ex., Sansigolo, 1998). Para o Nordeste brasileiro (ou suas regiões), os estudos abordam vários aspectos dos eventos de $\mathrm{PE}$, como a

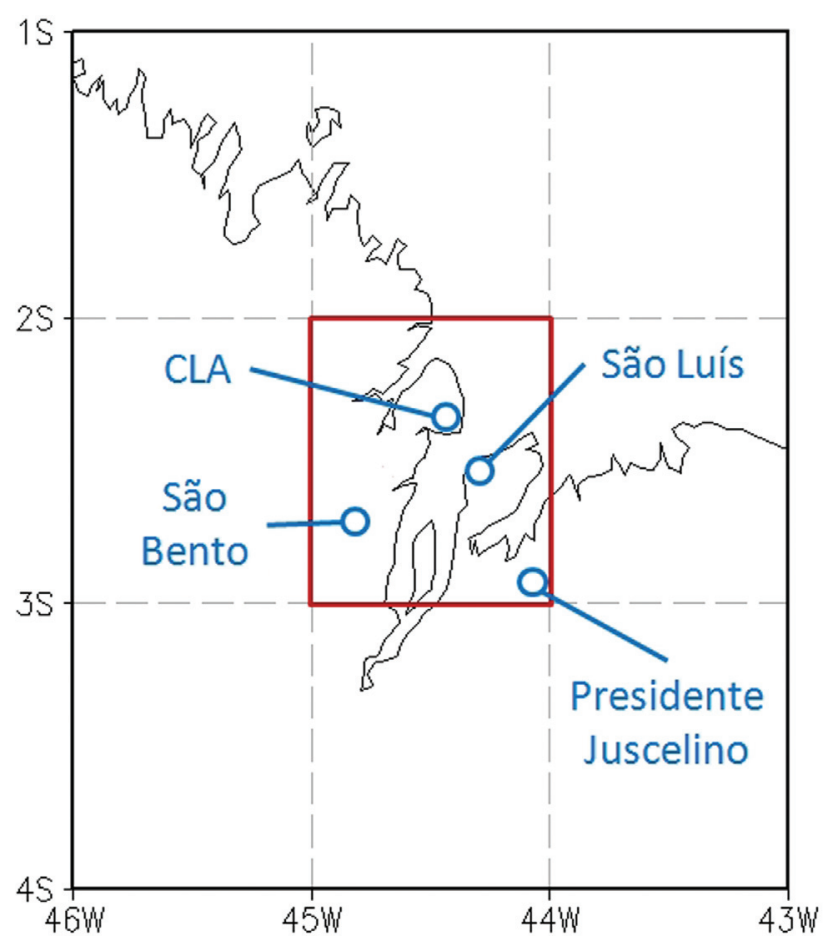

Figura 1 - Localização aproximada do CLA e das cidades maranhenses mencionadas no texto: São Luís, São Bento e Presidente Juscelino (ćŕrculos azuis). A região do CLA corresponde ao domínio de $1^{\circ} \times 1^{\circ}$ (retângulo vermelho). caracterização climatológica e modelagem estatística dos eventos, a análise da tendência e da variabilidade interanual, o estudo e a simulação de eventos, a identificação de padrões sinóticos associados aos eventos e o impacto de mudanças climáticas globais na frequência de eventos (p. ex., Torres e Ferreira, 2011; Andrade e Lima, 2013; Oliveira, 2014a; Vieira, 2014).

Para a região do CLA, embora não haja um estudo específico, algumas características dos eventos de PE podem ser estimadas da literatura. Por exemplo, com base nos trabalhos de Costa et al. (2007), Grimm e Tedeschi (2009), Gonçalves (2011), Andrade e Lima (2013), e Vieira (2014):

i. os eventos de PE seriam mais frequentes no trimestre chuvoso (março a maio);

ii. no bimestre de março e abril, maior (menor) frequência de eventos estaria associada à condição de La Niña (El Niño) no Pacífico equatorial e/ou a maior (menor) total bimestral de precipitação;

iii. os eventos poderiam ser modelados estatisticamente pela distribuição de Gumbel, e a precipitação de 1 dia com tempo de retorno de 100 anos estaria dentre $170 \mathrm{e}$ $210 \mathrm{~mm}$;

iv. para as excedências, haveria uma tendência de aumento na série histórica; e

v. as projeções de clima futuro indicariam aumento da frequência de eventos.

Existe incerteza nessas estimativas, pois os valores encontrados na literatura referem-se a regiões que extrapolam a região do CLA ou se limitam a uma única localidade da região (como a cidade de São Luís; Fig. 1). Assim, ao focar a região do CLA, um dos objetivos específicos do presente trabalho é verificar as 3 primeiras estimativas (i-iii).

Uma questão em aberto é se existem características que distinguem os eventos de PE dos de precipitação intensa, mas não-extrema, na região do CLA. No presente trabalho, essa questão é abordada a partir de dois pontos de vista distintos utilizando somente dados observados. No primeiro, verifica-se a diferença no padrão espacial de atividade convectiva, utilizando dados de Radiação de Onda Longa Emergente (ROLE). No segundo, verifica-se a diferença nas características dos totais horários de precipitação coletados no CLA (p. ex., número de horas com chuva e/ou total horário máximo).

Portanto, sumariando, o presente trabalho enfoca os eventos de PE na região do CLA e possui dois objetivos específicos. O primeiro consiste em identificar os eventos, analisar o ciclo anual e a variabilidade interanual, e realizar a modelagem estatística. Esse objetivo, por um lado, possui um caráter confirmatório, pois há estimativas da literatura; por outro lado, contribui ao prover informações mais precisas para a região do CLA. O segundo consiste em investigar o que distingue os eventos de PE dos demais de precipitação intensa, mas não-extrema, na região do CLA, em termos do padrão espacial de atividade convectiva e das 
características dos totais horários de precipitação. Esse objetivo aborda um aspecto novo e procura ampliar o conhecimento sobre as características dos eventos de PE.

$\mathrm{O}$ trabalho está organizado da seguinte forma. Os dados e a metodologia são apresentados nas seções 2 e 3, respectivamente. Na seção de resultados (seção 4), inicialmente, realiza-se uma caracterização geral dos eventos (como a apresentação do ciclo anual), seguida da modelagem estatística (seção 4.1). Então, para o bimestre de março e abril, analisam-se a variabilidade interanual (seção 4.2), o padrão horizontal de atividade convectiva (somente para o bimestre de 1996; seção 4.3) e os totais horários (seção 4.4). As considerações finais (seção 5) incluem as conclusões e uma descrição dos eventos de PE sobre a região do CLA que sintetiza alguns resultados obtidos.

\section{Dados}

\subsection{Totais diários de precipitação}

Uma escolha importante refere-se ao conjunto de dados a partir dos quais os eventos de PE são identificados. No presente trabalho, opta-se por utilizar os totais diários de precipitação do Climate Prediction Center (CPC) / National Oceanic and Atmospheric Administration (NOAA). Os dados baseiam-se em medidas de pluviômetros interpolados para uma grade regular de $0,5^{\circ} \times 0,5^{\circ}$. Embora não seja longo (1979 em diante), o conjunto possui dados de qualidade, com pouquíssimas falhas e boa resolução espacial, gerados por meio da aplicação da técnica de interpolação ótima (Xie et al., 2007). O conjunto vem sendo utilizado em estudos para o Nordeste brasileiro, como o de Farias et al. (2012) para o Sertão pernambucano e o de Pinheiro e Oyama (2013) para a região do CLA. Por outro lado, como o conjunto é de domínio público e pode ser acessado pela internet (http://ftp.cpc.ncep.noaa.gov/precip/CPC_UNI_ PRCP/GAUGE_GLB/), garante-se a que os resultados do presente trabalho podem ser replicados.

São utilizados os totais diários do CPC-NOAA para o período de 30 anos de set-1984 a ago-2014. O total diário de precipitação para a região do CLA é calculado como a média na área compreendida pelos quatro pontos de grade que circundam o CLA (Pinheiro e Oyama, 2013). Logo, os totais diários são representativos de uma área de $1^{\circ} \times 1^{\circ}$ aproximadamente centrada no CLA, que é doravante chamada de domínio (Fig. 1). O total diário refere-se a 12 UTC, ou seja, representa a precipitação acumulada em $24 \mathrm{~h}$ desde 12 UTC do dia anterior.

\subsection{Totais horários de precipitação}

Os totais horários de precipitação provêm do pluviômetro instalado na estação meteorológica de superfície do CLA (2²0' S; 44⒉ $5^{\prime}$ W; 49 m; Marques e Fisch, 2005). Os dados encontram-se disponíveis a partir de 17-ago1993. No presente trabalho, somente os dados do bimestre de março e abril no período de 1994 a 2014 (21 anos) são utilizados; esses dados podem ser acessados pela internet (https://sites.google.com/site/mdoyama2002/Home/dados). Somente os dias com mais de 20 horas de dados válidos (ou seja, sem falhas) são considerados (esse procedimento elimina cerca de $25 \%$ dos dias).

\subsection{Outros conjuntos de dados}

Os dados de ROLE, Temperatura da Superfície do Mar (TSM) e vento em 925 hPa provêm do Earth System Research Laboratory / National Oceanic and Atmospheric Administration (ESRL/NOAA).

- Os dados de ROLE pertencem ao conjunto "NOAA Interpolated OLR" (Liebmann, 1996) e estão disponíveis de jun-1974 a dez-2013. Os dados são diários e encontram-se dispostos em uma grade regular de $2,5^{\circ} \times 2,5^{\circ}$. No presente trabalho, os dados do bimestre de março e abril de 1996 são utilizados. O valor de ROLE sobre a região do CLA corresponde ao do ponto de grade centrado em $2,5^{\circ} \mathrm{S}$ e $45^{\circ} \mathrm{W}$.

- Os dados de TSM pertencem ao conjunto "NOAA Extended Reconstructed SST/V3b" (Smith et al., 2008) e estão disponíveis de 1854 até o presente. Os dados são mensais, encontram-se dispostos em uma grade regular de $2^{\circ} \times 2^{\circ}$ e são usados para computar dois índices: o Niño-3 e o gradiente inter-hemisférico de TSM do Atlântico (GRAD). Inicialmente, as anomalias de TSM são obtidas considerando o período 1951-2010 como base. Então, o índice Niño-3 é calculado como a média das anomalias na área $\left[150^{\circ} \mathrm{W}-90^{\circ} \mathrm{W} ; 6^{\circ} \mathrm{S}-6^{\circ} \mathrm{N}\right]$. GRAD é calculado como a diferença da média de anomalias entre duas áreas: $\left[60^{\circ} \mathrm{W}-20^{\circ} \mathrm{W}\right.$; Equador $\left.-20^{\circ} \mathrm{N}\right]$ e $\left[30^{\circ} \mathrm{W}-\right.$ $10^{\circ} \mathrm{E} ; 20^{\circ} \mathrm{S}$-Equador]. GRAD positivo (negativo) aponta para norte (sul). A definição dos índices baseia-se em Andreoli e Kayano (2007). No presente trabalho, os índices Niño-3 e GRAD do bimestre de março e abril no período 1985 a 2014 (30 anos) são utilizados.

- Os dados de vento em $925 \mathrm{hPa}$ pertencem ao conjunto "NCEP/NCAR Reanalysis" (Kalnay et al., 1996; Kistler et al., 2001) e estão disponíveis de 1948 até o presente em várias frequências temporais (4 vezes ao dia, diária, mensal). Os dados encontram-se dispostos em uma grade regular de $2,5^{\circ} \times 2,5^{\circ}$. No presente trabalho, os dados mensais para o bimestre de março e abril no período 1985 a 2014 (30 anos) são utilizados. O valor de vento em $925 \mathrm{hPa}$ sobre a região do CLA corresponde ao do ponto de grade centrado em $2,5^{\circ} \mathrm{S}$ e $45^{\circ} \mathrm{W}$.

Todos esses conjuntos de dados são de domínio público e podem ser acessados pela internet (http://www.esrl.noaa.gov/psd/data/gridded).

\section{Metodologia}

\subsection{Identificação dos eventos de $\mathbf{P E}$}

Os eventos de PE são identificados com base nos totais diários do CPC/NOAA para o domínio. Adota-se o 
$99^{\circ}$ percentil $\left(P_{99}\right)$ dos totais diários como o limiar de PE (p. ex., Villarini et al., 2011; Andrade e Lima, 2013). Assim, nos dias de PE, o total diário é superior ao limiar; nos de precipitação não-extrema, inferior. Para cada dia de $\mathrm{PE}$, a excedência corresponde à diferença entre o total diário e o limiar. Os dias de PE são agrupados em eventos de PE.

- Cada dia de PE isolado (ou seja, quando tanto o dia anterior quanto o posterior são de precipitação não-extrema) corresponde a um evento, e a excedência do evento coincide com a do dia (p. ex., A e C na Fig. 2).

- No caso de dias consecutivos de PE, cada grupo de dias consecutivos é considerado um único evento com excedência igual à máxima entre os dias do grupo (p. ex., B na Fig. 2) (Tomassini e Jacob, 2009).

O procedimento de agrupamento leva a eventos de PE que podem ser considerados independentes, pois são separados por no mínimo 1 dia de precipitação não-extrema. Esse critério de independência, embora muito simples, tem sido adotado na literatura (p. ex., Yiou et al., 2008).

\subsection{Análise de tendência}

$\mathrm{Na}$ análise da tendência das séries temporais anuais da frequência de eventos e das excedências (Cf. Villarini et al., 2011), aplicam-se os testes de Mann-Kendall e da reta de regressão. A verificação da estacionaridade dessas séries é uma etapa prévia da modelagem estatística (seção 3.3).

No teste de Mann-Kendall, para uma dada série temporal, a hipótese de que não há tendência é rejeitada se:

$$
|Z|>Z_{\alpha / 2}
$$

onde $Z$ é a estatística normalizada do teste, e $Z_{\alpha / 2}$ é um valor crítico obtido da distribuição normal com nível de teste $\alpha$

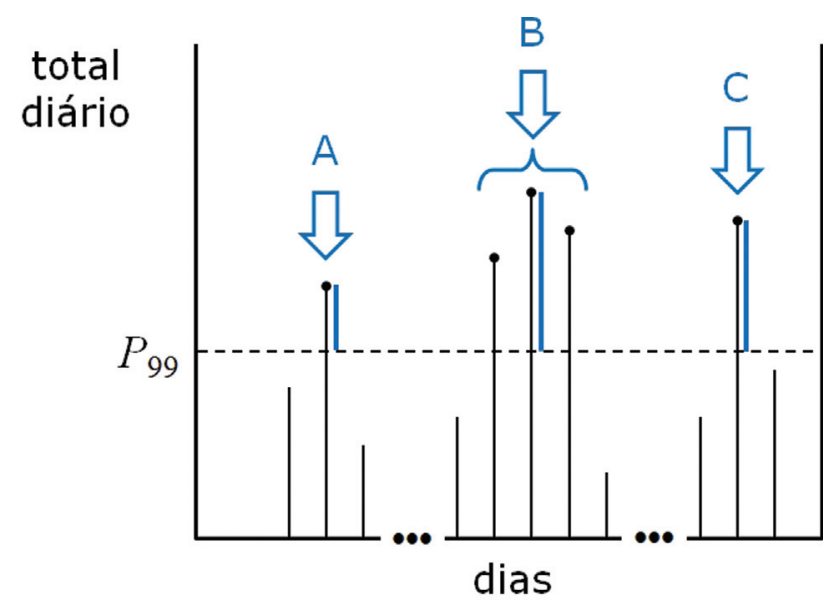

Figura 2 - Ilustração da identificação dos eventos de PE. Nos dias de PE, os totais diários são superiores ao $99^{\circ}$ percentil $\left(P_{99}\right)$ e estão indicados por círculos pretos, e as excedências correspondem à diferença entre os totais diários e $P_{99}$. Cada seta azul representa um evento PE, e a excedência dos eventos está representada pelos segmentos azuis. Os eventos A e C referem-se a dias de PE isolados; logo, a excedência desses eventos corresponde à dos dias. $\mathrm{O}$ evento $\mathrm{B}$ contém três dias de $\mathrm{PE}$ consecutivos, $\mathrm{e}$ a excedência do evento é a maior entre os dias que o compõem. (bilateral). A forma de cálculo de $Z$ está mostrada em diversos textos (p. ex., Ahmad et al., 2015). Sinal positivo (negativo) de $Z$ indica tendência de crescimento (redução). Para $\alpha=5 \%$, o valor crítico $\left(Z_{2,5 \%}\right)$ é igual a 1,96 .

Para uma dada série temporal, o coeficiente angular da reta de regressão representa a tendência. A hipótese de que não há tendência (coeficiente angular nulo) equivale à de ausência de correlação linear (Costa Neto, 1977). Essa hipótese é rejeitada se:

$$
\left|R \sqrt{\frac{n-2}{1-R^{2}}}\right|>t_{n-2, \alpha / 2}
$$

onde $R$ é o coeficiente de correlação linear, $n$ é o tamanho da série, e $t_{n-2, \alpha / 2}$ é um valor crítico obtido da distribuição $t$ de Student com $n-2$ graus de liberdade e nível de teste $\alpha$ (bilateral). Para $n=30$ e $\alpha=5 \%, t_{28,2,5 \%}=2,048$; utilizando a Eq. (2), a hipótese não pode ser rejeitada se $|R|>0,36$.

\subsection{Modelagem estatística}

A caracterização estatística de extremos pode ser obtida de dois tipos de série: a de Máximos Anuais (MA), que considera apenas o maior valor de total diário de cada ano, e a de Duração Parcial (DP), que seleciona os dias cujo total é superior a um determinado limiar (Naghettini e Pinto, 2007). A modelagem estatística baseada diretamente em séries de MA é adequada para séries longas. Para séries curtas, como a do presente trabalho (30 anos; totais diários do CPC/NOAA), a distribuição de MA é obtida a partir da série de DP.

A distribuição de Gumbel é uma das distribuições de extremos mais comuns e tem sido utilizada com sucesso para representar a distribuição de MA de precipitação para localidades no Brasil (p. ex., Sansigolo, 1998) e no Nordeste brasileiro (p. ex., Costa et al., 2007; Vieira, 2014). O procedimento para se chegar aos parâmetros da distribuição de Gumbel a partir da série de DP é explicada a seguir (Cf. Naghettini e Pinto, 2007).

Como ponto de partida, considera-se que as séries temporais de frequência e excedências anuais de eventos de PE são estacionárias. Então, em primeiro lugar, verifica-se a hipótese de que a frequência anual de eventos de PE segue a distribuição de Poisson. O parâmetro da distribuição é a média $(v)$, ou seja, ao número total de eventos de PE dividido pelo número de anos $(n=30)$. Segundo o teste de Cunnane, a hipótese é rejeitada se:

$$
\gamma=\sum_{i}\left(\frac{N_{i}-v}{v}\right)^{2} \geq \chi_{\alpha, n-1}^{2}
$$

onde $N_{i}$ é o número de eventos de PE no ano $i$, e $\chi_{\alpha, n-1}^{2}$ refere-se à distribuição qui-quadrado com $n-1$ graus de liberdade e nível de teste $\alpha$. Para $n=30$ e $\alpha=5 \%, \chi_{5 \%, 29}^{2}=$ 42,6 . 
Em segundo lugar, verifica-se a hipótese de que as excedências seguem a distribuição exponencial. O parâmetro da distribuição é a média $(\theta)$, ou seja, a excedência média por evento. A aderência é avaliada pelo teste de Kolmogorov-Smirnov. A hipótese é rejeitada se a máxima diferença em módulo entre a função de probabilidade acumulada empírica e teórica (da distribuição exponencial) é maior que um valor crítico $\left(D_{c r}\right)$. Para um número de eventos $\left(n_{e}\right) \geq 40$ e nível de teste de $5 \%, D_{c r}$ é dado por:

$$
D_{c r}=\frac{1,3581}{\sqrt{n_{e}}} \text {. }
$$

Se duas condições referentes à série de DP são válidas, ou seja, se:

- a frequência anual de eventos de PE segue a distribuição de Poisson com parâmetro $v$,

- e as excedências seguem a distribuição exponencial com parâmetro $\theta$,

então a distribuição de MA segue a distribuição de Gumbel. A função acumulada da distribuição é dada por:

$$
\begin{aligned}
& F(x)=\exp \left[-\exp \left(-\frac{x-\beta}{\alpha}\right)\right] \\
& \alpha=\theta \\
& \beta=P_{99}+\theta \cdot \ln (v)
\end{aligned}
$$

onde $x$ é o total diário de precipitação; $\alpha$, o parâmetro de escala; e $\beta$, o parâmetro de posição.

A partir da Eq. (5), obtém-se a relação entre precipitação diária $\left(P, \mathrm{~mm} \mathrm{~d}^{-1}\right)$ e tempo de retorno $(T$, anos):

$$
\begin{aligned}
& T=\frac{1}{1-F} \\
& P=\beta-\alpha \cdot \ln \left[\ln \left(\frac{T}{T-1}\right)\right] .
\end{aligned}
$$

\subsection{Correlação parcial}

Para estudar os fatores associados à variabilidade interanual da frequência de eventos, utiliza-se o conceito de correlação parcial. Para fins de ilustração, sejam dois fatores, $X$ e $Y$, que estariam relacionados a uma variável $Z$. Três pares de correlação podem ser computados: $Z$ e $X$ $\left(R_{Z X}\right), Z$ e $Y\left(R_{Z Y}\right)$, e $X$ e $Y\left(R_{X Y}\right)$. Suponhamos que a influência de $X$ em $Z$ se dê por duas vias: na primeira, $X$ influencia $Z$ por meio de $Y$ (ou $X$ influencia $Y$, e $Y$ influencia $Z$ ); na segunda, $X$ influencia $Z$ diretamente, sem a mediação de $Y$. A correlação entre $Z$ e $X\left(R_{Z X}\right)$ engloba as duas vias, enquanto a correlação entre $Z$ e $Y\left(R_{Z Y}\right)$ inclui a primeira via. A segunda via corresponde à correlação parcial entre $Z \mathrm{e} X$, ou seja, excluindo a influência de $Y$ (ou descontando o efeito de $Y$ ), e é dada por (Costa Neto, 1977):

$$
R_{Z X, Y}=\frac{R_{Z X}-R_{Z Y} \cdot R_{X Y}}{\sqrt{\left(1-R_{Z Y}^{2}\right) \cdot\left(1-R_{X Y}^{2}\right)}} .
$$

A significância estatística da correlação parcial é testada por meio de uma relação semelhante à Eq. (2), mas substituindo o número de graus de liberdade de $n-2$ por $n$ - 2 - $k$, onde $k$ é o número de fatores cuja influência é excluída. Para a correlação parcial dada pela Eq. (10), $k=1$, e a hipótese de ausência de correlação parcial é rejeitada se:

$$
\left|R_{Z X, Y} \sqrt{\frac{n-3}{1-R_{Z X, Y}^{2}}}\right|>t_{n-3, \alpha / 2} .
$$

Para $n=30$ e $\alpha=5 \%, t_{27,2,5 \%}=2,052$; utilizando a Eq. (11), a hipótese não pode ser rejeitada se $\left|R_{Z X, Y}\right|>0,37$.

\subsection{Agrupamento por meio de tercis}

Para agrupar os dados, o método dos tercis é utilizado na obtenção de alguns resultados. O método consiste em ordenar o conjunto de dados em ordem decrescente e dividir o conjunto ordenado em três partes iguais. $O$ terço inferior contém os dados cujo valor é menor que o primeiro tercil; o superior, maior que o segundo tercil; e o intermediário, entre os dois tercis.

\section{Resultados}

A Fig. 3 mostra as frequências relativas acumuladas do total diário de precipitação para valores superiores à mediana. Precipitação intensa (total diário $\geq 10 \mathrm{~mm} \mathrm{~d}^{-1}$ ) ocorre em cerca de $20 \%$ dos dias; muito intensa $\left(\geq 20 \mathrm{~mm} \mathrm{~d}^{-1}\right.$ ), entre 5 e $10 \%$ (a definição de precipitação intensa e muito intensa segue Tank et al., 2009). O limite superior dos totais diários, chamado de precipitação diária máxima, é igual a $143,5 \mathrm{~mm} \mathrm{~d}^{-1}$ e ocorreu no dia 11-mai-2014 (12 UTC do dia 10 a 12 UTC do dia 11). Para

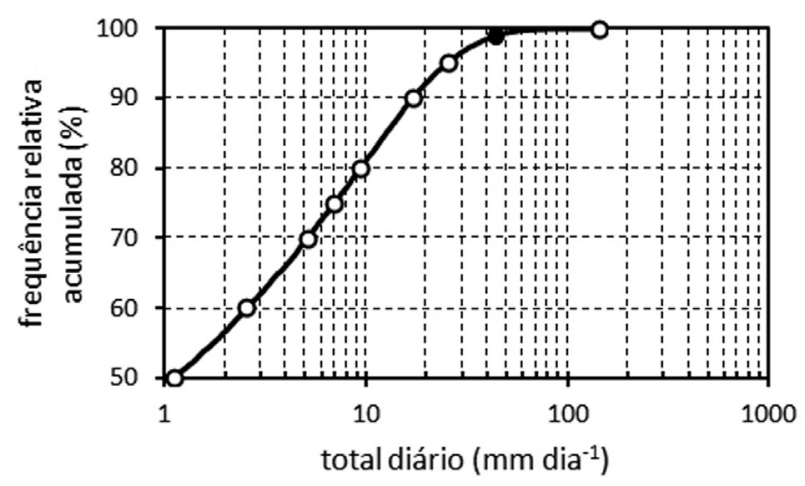

Figura 3 - Frequência relativa acumulada dos totais diários de precipitação para o período de set-1984 a ago-2014 (30 anos). A relação é mostrada somente para os totais superiores à mediana. Na curva, os pontos referentes a alguns percentis - mediana, sexto ao nono decil, terceiro quartil, e $95^{\circ}$ e $99^{\circ}$ percentis - e à precipitação diária máxima no período $\left(143,5 \mathrm{~mm} \mathrm{~d}^{-1}\right)$ estão indicados por círculos. O círculo preenchido corresponde ao $99^{\circ}$ percentil. 
esse dia, a estação meteorológica de São Luís registrou o maior valor de precipitação diária $\left(182,0 \mathrm{~mm} \mathrm{~d}^{-1}\right)$ da série histórica a partir de 1961 (Instituto Nacional de Meteorologia, 2014), e alagamentos e inundações foram reportados na cidade pelos meios de comunicação.

O $99^{\circ}$ percentil, que corresponde ao limiar de PE adotado no presente trabalho, é igual a $44 \mathrm{~mm} \mathrm{~d}^{-1}$. Esse valor encontra-se no interior do intervalo de limiares de PE adotados por diversos estudos ao redor do mundo (entre 20 e $100 \mathrm{~mm} \mathrm{~d}^{-1}$; Easterling et al., 2000). Os dias de PE totalizam 110 dias, e são quase igualmente divididos entre dias muito úmidos ( $48 \%$ dos dias) e extremamente úmidos ( $52 \%$ dos dias) (a definição de dias úmidos e muito úmidos segue Tank et al., 2009). Os 110 dias de PE correspondem a 104 eventos, pois há 6 eventos com 2 dias consecutivos de PE. Logo, quase todos os eventos (94\%) são compostos por dias isolados de PE. A duração dos poucos eventos com dias consecutivos de PE (6\%) limita-se a 2 dias.

$\mathrm{O}$ ciclo anual da frequência de eventos de PE e das excedências está mostrado na Fig. 4. Ambos são muito semelhantes ao ciclo anual da precipitação. Em termos sazonais, isso significa a ocorrência de máximo (mínimo) no trimestre MAM (SON), quando a frequência média de eventos é igual a $0,69(0,02)$ mês $^{-1}$ ano $^{-1}$, e a excedência média, igual a $9,36(0,04) \mathrm{mm}^{\text {mês }}{ }^{-1} \mathrm{ano}^{-1}$. Os resultados confirmam os obtidos por Andrade e Lima (2013) para os eventos de PE na porção norte do Nordeste brasileiro, onde se encontra o CLA.

Os meses de março e abril, que são os mais chuvosos na região do CLA (Pereira et al., 2002), são os que concentram a maior frequência de eventos (quase metade do total). Como não ocorrem eventos de agosto a outubro nos anos considerados, define-se ano hidrológico como o período de 12 meses a partir de setembro.

A estação chuvosa na região do CLA, que se estende climatologicamente do final de janeiro a meados de junho

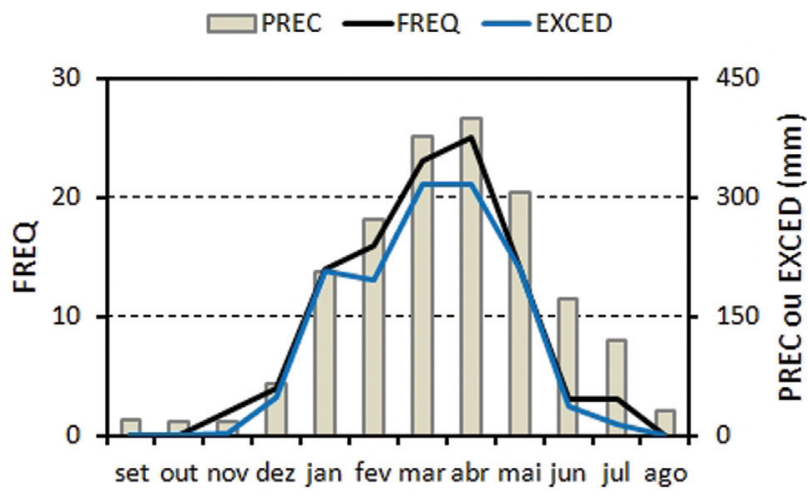

Figura 4 - Totais mensais da frequência de eventos de PE (FREQ, linha preta, eixo vertical à esquerda) e das excedências (EXCED, linha azul, eixo vertical à direita) para o período de set-1984 a abr-2014 (30 anos). As médias mensais de FREQ e EXCED podem ser computadas dividindo os totais mensais pelo número de anos (30). A precipitação média mensal para o período está também mostrada (barras cinzas, eixo vertical à direita).
(Pinheiro e Oyama, 2013), concentra quase $90 \%$ dos eventos. Nessa estação, como as excedências possuem um ciclo anual semelhante ao da frequência, a excedência por evento é em média praticamente constante ( $\sim 15 \mathrm{~mm}$ por evento).

\subsection{Modelagem estatística}

Para fins de modelagem estatística, verifica-se, inicialmente, a existência de tendências significativas nas séries temporais dos totais anuais da frequência de eventos de PE e das excedências (p. ex., Villarini et al., 2011). As séries apresentam variabilidade interanual expressiva sobreposta a ligeira tendência de aumento, como ilustrado pelas retas de regressão linear (Fig. 5). Essa tendência de aumento vai ao encontro de resultados de estudos anteriores (como Vieira, 2014, para a frequência de eventos em São Luís, e Oliveira, 2014a, para as excedências na porção central do Maranhão). No entanto, como a série utilizada no presente trabalho é relativamente curta (30 anos), a tendência pode não representar a mudança monotônica e lenta da média, mas ser o reflexo de variabilidades naturais em escalas mais longas que a decenal (p. ex., Andreoli et al., 2004).

Em relação à significância, para a frequência de eventos, a tendência não é significativa a um nível de teste de $5 \%$ tanto para o teste de Mann-Kendall $(Z=0,78<1,96)$ quanto para o do coeficiente angular da reta de regressão $(|R|=0,17<0,36)$. Para as excedências, no entanto, a tendência é significativa em ambos os testes $(Z=2,03>1,96$ e $|R|=0,45>0,36)$, mas o nível de significância é fortemente dependente de um único evento, o da precipitação diária máxima (ocorrido no dia 11-mai-2014). Se esse evento for eliminado, a excedência de 2014 diminui substancialmente e a tendência passa a não ser significativa em ambos os testes $(Z$ passa a 1,21 , e $|R|$, a 0,31 ; a reta de regressão muda para a linha vermelha tracejada na Fig. 5); em relação à frequência de eventos, a tendência mantém-se não-significativa $(Z$ passa a 0,57 , e

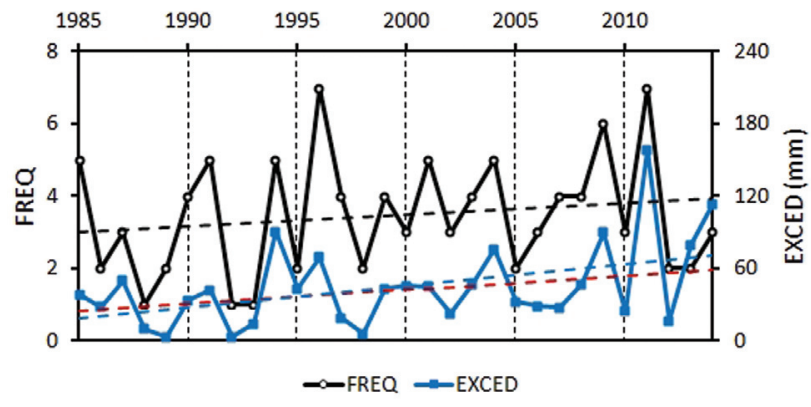

Figura 5 - Totais anuais da frequência de eventos de PE (FREQ, linha preta com círculos) e das excedências (EXCED, linha azul com quadrados) para o período de 1985-2014 (considerando ano hidrológico, ou seja, período de 12 meses a partir de setembro do ano anterior). As retas de regressão linear para a frequência de eventos (linha preta tracejada) e as excedências (linha azul tracejada) estão mostradas. Desconsiderando a precipitação diária máxima, a reta de regressão para as excedências tornase a linha vermelha tracejada. 
$|R|$, a 0,13$)$. Assim, para que a condição de estacionaridade seja satisfeita, retira-se o evento da precipitação máxima diária da série para a modelagem estatística. Com isso, a frequência de eventos passa de 104 a 103 em 30 anos (isso afeta a média de eventos por ano de 3,47 a 3,43, e a média de excedência por evento de 12,95 a $12,11 \mathrm{~mm}$ ), e as séries passam a ter tendência não-significativa no período de 1985 a 2014.

A aplicação do teste de Cunnane mostra que, a um nível de teste de $5 \%$, pode-se aceitar a hipótese de que o valor anual do número de eventos segue a distribuição de Poisson com média (v) igual a 3,43 eventos $a^{-1} o^{-1}$ Em relação às excedências, a Fig. 6 mostra que há, visualmente, uma boa aderência entre as distribuições acumuladas empírica e exponencial. Isso é confirmado pelo teste de aderência. A aplicação do teste de Kolmogorov-Smirnov mostra que, a um nível de significância de 5\%, pode-se aceitar a hipótese de que as excedências dos 103 eventos de PE seguem a distribuição exponencial com média $(\theta)$ igual a $12,11 \mathrm{~mm}$ (por evento).

Como o valor anual do número de eventos de EP segue a distribuição de Poisson, e as excedências por evento seguem a distribuição exponencial, então os máximos anuais (de total diário de precipitação) seguem a distribuição de Gumbel. Os parâmetros da distribuição são:

- parâmetro de escala $(\alpha)=\theta=12,110 \mathrm{~mm}$;

- parâmetro de posição $(\beta)=P_{99}+\theta \ln (v)=58,942 \mathrm{~mm}$.

Utilizando esses valores, a precipitação de 1 dia com tempo de retorno de 100 anos (precipitação centenária) é de $115 \mathrm{~mm}$. Nos 30 anos analisados (1985-2014), a precipitação centenária é excedida em somente dois eventos: o da precipitação diária máxima, ocorrida em 11-mai-2014 (de 143,5 mm), e o de 08-jan-2011 (140,8 mm).

$\mathrm{Na}$ literatura, encontram-se vários valores de precipitação centenária para localidades no interior do domínio (Fig. 1): 196-283 mm para São Luís (p. ex., Costa et al., 2007; Gonçalves, 2011; Vieira, 2014), $192 \mathrm{~mm}$ para Presidente Juscelino e $218 \mathrm{~mm}$ para São Bento (estimados de

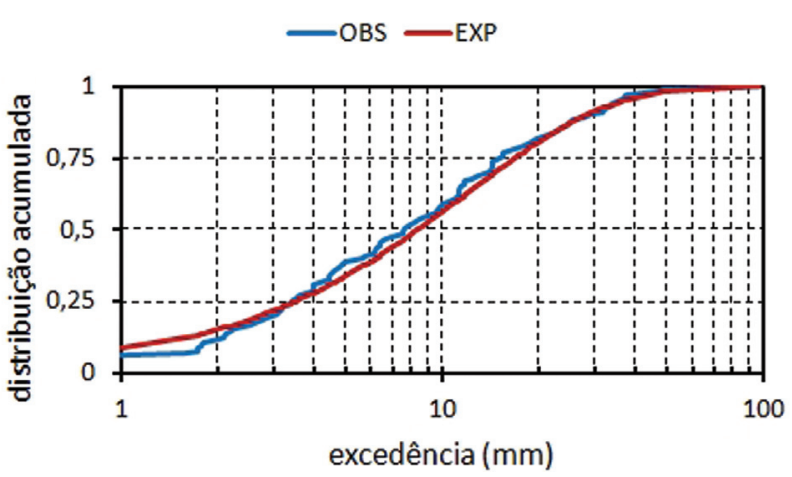

Figura 6 - Distribuição acumulada das excedências. Linha azul: distribuição observada (OBS); linha vermelha: distribuição exponencial (EXP).
Sousa, 2007). Como a média em área suaviza os picos de totais diários, a precipitação centenária no domínio tende a ser menor que a de localidades no seu interior, e uma estimativa (Cf. Vieira, 2014) é que esteja entre 170 e $210 \mathrm{~mm}$ (como mencionado anteriormente na seção 1). O valor obtido no presente trabalho, de $115 \mathrm{~mm}$, encontra-se muito abaixo do limite inferior desse intervalo e, assim, precisa ser tomado com cautela, embora discrepâncias dessa magnitude já tenham sido reportadas por Costa et al. (2007) ao comparar a precipitação centenária de São Luís obtida de dados de 5 estações pluviométricas distintas com outras 3 estimativas.

\subsection{Variabilidade interanual no bimestre de março $\mathrm{e}$ abril}

Como mostrado anteriormente (Fig. 5), a ocorrência de eventos de PE possui uma clara e expressiva variabilidade interanual. Por exemplo, em alguns anos ocorrem mais de 6 eventos, em outros, somente 1 . Uma hipótese é que essa variabilidade estaria diretamente relacionada à variabilidade do total de precipitação (p. ex., Grimm e Tedeschi, 2009; Andrade e Lima, 2013). A justificativa seria que a existência de condições atmosféricas e/ou oceânicas associadas à maior (menor) ocorrência de eventos de precipitação também favoreceria (inibiria) a ocorrência de eventos de PE. Para verificar a hipótese, analisa-se o bimestre de março e abril, quando ocorre a maior frequência de eventos (em média, 1,6 evento por ano; Fig. 4).

As séries temporais da frequência de eventos de PE e do total de precipitação no bimestre (anomalias normalizadas) estão mostradas na Fig. 7. As séries mostram uma relativa concordância entre si, o que vai ao encontro da hipótese. Em 18 dos 30 anos (ou seja, em 60\% dos anos), as anomalias de ambas as variáveis possuem o mesmo sinal, e há uma concordância evidente dos valores na década de 1992 a 2001. Nos anos com anomalias de maior magnitude (> 1 desvio-padrão), há uma concordância notável em 1992, 1996, 2000, 2005 e 2014, embora haja também dis-

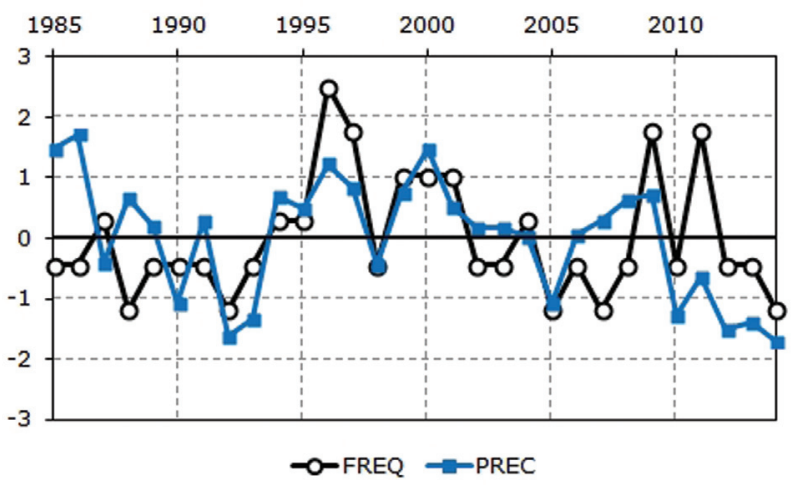

Figura 7 - Valores normalizados (anomalia dividido pelo desvio-padrão) da frequência de eventos de PE (FREQ) e da precipitação (PREC) para o bimestre de mar-abr entre 1985 e 2014. 
cordâncias expressivas, particularmente em anos no início (1985, 1986 e 1988) e no final (2007 e 2011) da série.

Ocorre correlação significativa (nível de teste de $95 \%$ ) de $+0,44$ entre a frequência de eventos de PE e o total de precipitação no bimestre (Fig. 8), o que confirma a hipótese de que as variáveis estão relacionadas. No entanto, a fração de variância da frequência de eventos explicada pela precipitação é de somente $\sim 20 \%$, ou seja, relativamente baixa. Isso motiva a busca por outros fatores explicativos, tais como índices oceânicos (índice Niño-3 e GRAD) e dinâmicos [magnitude (MAG) e direção do vento (DIR) em $925 \mathrm{hPa}$ sobre o CLA]. Por exemplo, para o norte do Nordeste brasileiro, no bimestre de março e abril, a relação entre a frequência de eventos e o fenômeno El Niño / Oscilação Sul (ENOS) foi encontrada por Grimm e Tedeschi (2009), e Andrade e Lima (2013).

A frequência de eventos de PE possui correlação linear significativa não somente com o total de precipitação no bimestre, mas também com MAG ["R(FREQ,x)" na Fig. 8]. Como o total de precipitação está correlacionado de forma significativa com os demais fatores ["R(PREC,x)" na Fig. 8], obtém-se a correlação parcial entre a frequência eventos e os demais fatores excluindo a influência do total de precipitação. Os resultados mostram que a correlação parcial não é significativa para todos os demais fatores ["R(FREQ,x; PREC)" na Fig. 8]. Logo, os índices oceânicos (índice Niño-3 e GRAD) e dinâmicos (MAG e DIR) afetam a frequência de eventos indiretamente, via total de precipitação. A sugestão de que o fenômeno ENOS poderia afetar de forma expressiva a frequência de eventos independentemente da precipitação (Grimm e Tedeschi, 2009) não seria inteiramente válida para a região do CLA. Os

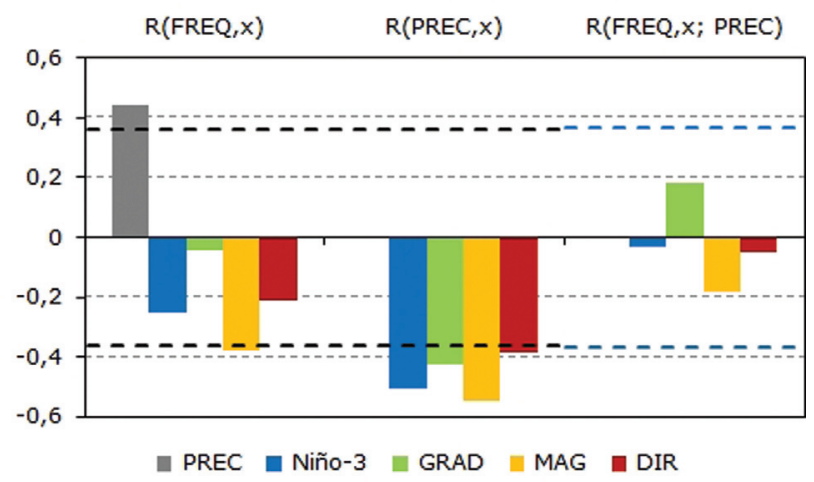

Figura 8 - Correlação entre a frequência de eventos de PE (FREQ) e os fatores [R(FREQ,x)], e entre a precipitação (PREC) e os fatores [R(PREC,x)], e correlação parcial entre FREQ e os fatores excluindo a influência de PREC [R(FREQ,x; PREC)]. Os fatores são: precipitação, índice Niño-3 (Niño-3), gradiente inter-hemisférico de TSM do Atlântico (GRAD), e magnitude (MAG) e direção (DIR) do vento em $925 \mathrm{hPa}$. Todas as variáveis referem-se ao bimestre de mar-abr. As correlações são computadas para o período de 1985-2014. As linhas horizontais tracejadas correspondem aos limiares de correlação para haver significância estatística a um nível de teste bilateral de 5\%: para correlação, $\pm 0,36$ (linha preta); para correlação parcial, $\pm 0,37$ (azul). fatores associados à fração de variância que não é explicada pelo total de precipitação $(\sim 80 \%)$ continuam desconhecidos.

\subsection{Padrão horizontal da atividade convectiva}

Para investigar se o padrão horizontal da atividade convectiva durante os eventos de PE possui características particulares que os distinguem dos dias de precipitação elevada, mas não-extrema, analisam-se os campos diários de ROLE, que é uma variável muito utilizada para identificar as áreas sob convecção profunda. Para dados diários, essas áreas podem ser delimitadas com o uso do limiar de ROLE de $230 \mathrm{~W} \mathrm{~m}^{-2}$ (Ferreira et al., 2005). Os resultados são obtidos somente para o bimestre de mar-abr de 1996, pois a maior frequência de eventos ( 5 eventos) ocorre nesse bimestre (Fig. 7), e um número maior de eventos é importante para fins de representatividade do ponto de vista amostral.

No bimestre de mar-abr de 1996, a precipitação na região do CLA é acima da média (Fig. 7) e está associada à ocorrência de La Niña no Pacífico equatorial (http://www.cpc.noaa.gov/products/analysis_monitoring/ ensostuff/ensoyears.shtml). Em média, no bimestre, a atividade convectiva profunda ocorre sobre uma ampla região orientada zonalmente que cobre a ZCIT Atlântica, o Nordeste brasileiro e a Amazônia (Fig. 9a). Há dois máximos, um sobre as porções central e oeste da Amazônia, e outro sobre a costa norte do Brasil. Esse padrão segue o esperado para o bimestre, quando a ZCIT atinge a posição mais austral (p. ex., Melo et al., 2009). Uma outra região onde há atividade convectiva, apesar da menor extensão espacial, inclui os Estados de Santa Catarina e Paraná (SC-PR). Nessa região, a atividade convectiva resulta da ação de complexos convectivos de mesoescala associada ao posicionamento do jato subtropical de altos níveis (Grimm, 2009).

Os 61 dias do bimestre são divididos em terços para os dados de total diário de precipitação e ROLE. Nos dias de precipitação elevada, considerados como os 13 dias em que o total diário pertence ao terço superior $(\geq 20,3 \mathrm{~mm})$, e a ROLE, ao inferior $\left(<177,8 \mathrm{~W} \mathrm{~m}^{-2}\right)$, o padrão médio de atividade convectiva (Fig. 9b) é semelhante à média mensal (Fig. 9a), com intensificação da convecção sobre algumas áreas, como a região do CLA (o que é esperado pela categorização), o sudoeste da Amazônia e SC-PR.

O padrão dos dias de precipitação elevada resulta da combinação de dois padrões bastante distintos. Dos 13 dias, nos $5 \mathrm{em}$ que a precipitação é extrema (total diário $\geq 44 \mathrm{~mm}$ ), a atividade convectiva concentra-se em algumas áreas bem delimitadas (Fig. 9c), como o sudoeste da Amazônia, a costa norte do Brasil e SC-PR; nos 8 dias restantes, a atividade convectiva encontra-se distribuída por toda a área, como a Amazônia (Fig. 9d). As diferenças são significativas em algumas regiões (Fig. 9e). 

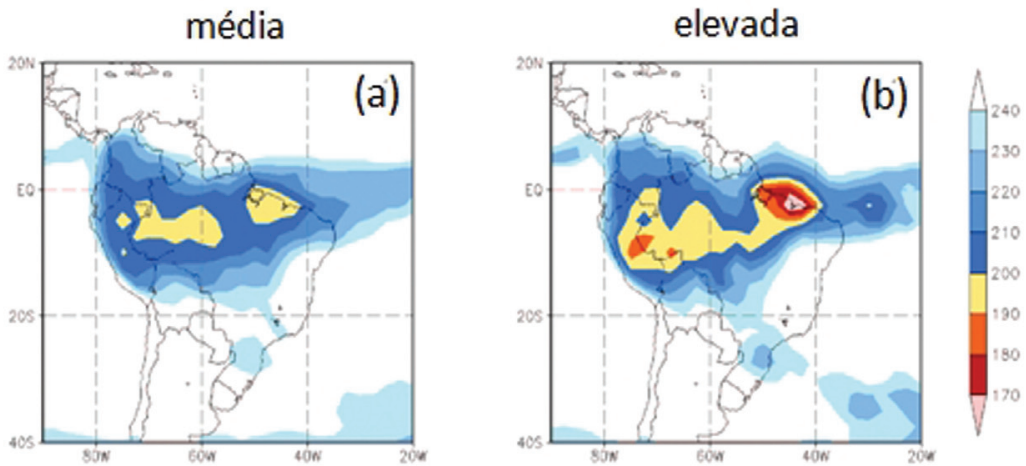

\section{elevada \& extrema}

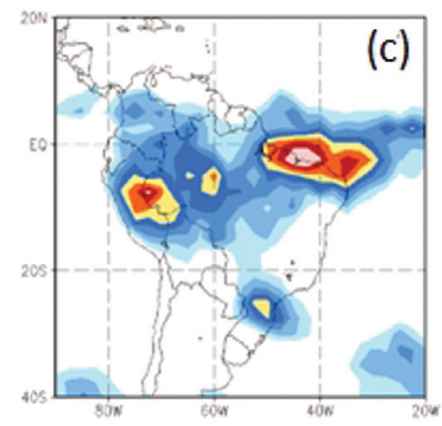

elevada \& não-extrema

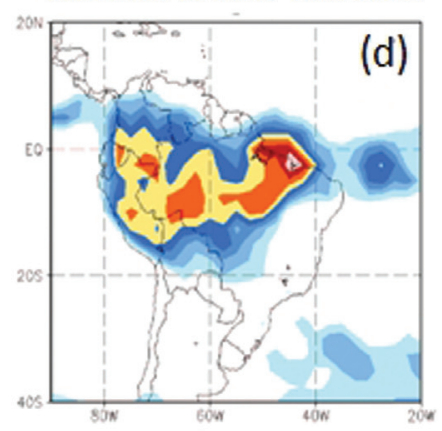

(c) $-(d)$

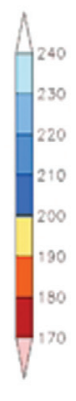

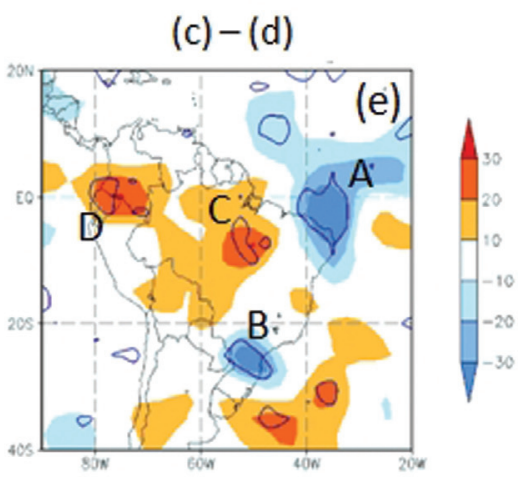

Figura 9 - Campos médios de Radiação de Onda Longa Emergente (ROLE) para o bimestre de março-abril de 1996 . A média é calculada para os 61 dias do bimestre (a) e os 13 dias de precipitação elevada (total diário no terço superior, i.e., $\geq 20,3$ mm, e ROLE no terço inferior, i.e., $\leq 177,8 \mathrm{~W}$ m²). Os 13 dias de precipitação elevada são divididos em duas categorias: os 5 dias de PE (i.e., total diário $\geq 44$ mm; média no painel "c") e os 8 dias restantes (i.e., de precipitação elevada mas não-extrema; média no painel "d"). As diferenças entre essas categorias (e) possuem significância estatística com nível de confiança de 90\% nas áreas limitadas por linhas azuis espessas. Algumas dessas áreas estão indicadas por letras (A a D).

- A partir da máxima atividade convectiva sobre o CLA, a faixa com convecção intensa nos 5 dias de PE estende-se na direção leste; nos 8 dias restantes, na direção sudoeste. Isso explica as diferenças significativas no oceano ao norte do Rio Grande do Norte e Ceará (região "A" na Fig. 9e) e no leste do Pará ("C").

- A convecção mais intensa sobre SC-PR (entre o oeste e noroeste da Amazônia), presente somente nos 5 dias de PE (8 dias restantes), explica a diferença significativa sobre a área "B" ("D").

- Sobre o sudoeste da Amazônia, a convecção mais intensa nos 5 dias de PE não leva a diferenças significativas em relação aos 8 dias restantes.

Logo, a ocorrência de atividade convectiva intensa sobre duas áreas - uma ampla e zonalmente alongada que cobre a costa norte do Brasil, e outra que cobre SC-PR diferencia os dias de PE dos demais de precipitação elevada. Utilizando imagens de satélite no canal infravermelho, Oliveira (2014b) mostrou que o evento de PE de 08-jan-2011 (total diário de $141 \mathrm{~mm} \mathrm{~d}^{-1}$ ), o segundo mais extremo no período de 1985-2014, esteve associado a uma ampla região de atividade convectiva sobre a costa norte do Brasil que persistiu durante todo o dia. Esse fato, embora se refira a um mês diferente do bimestre considerado, concorda com padrão obtido no presente trabalho para os dias de PE. Por outro lado, a possibilidade do total diário de precipitação sobre a região do CLA ser influenciado por fatores remotos, tal como a convecção sobre SC-PR, é um aspecto interessante, que vai ao encontro de estudos anteriores. Por exemplo, Oliveira e Oyama (2015) mostraram que, em julho, condições mais secas sobre o Sul e Sudeste brasileiro favoreceriam a iniciação de linhas de instabilidade na costa norte do Brasil. Mas ainda não é conhecido o mecanismo pelo qual a presença de condições mais úmidas sobre o Sul brasileiro, como a intensificação da atuação de complexos convectivos de mesoescala, poderia favorecer a convecção na costa norte do Brasil.

\subsection{Totais horários de precipitação nos dias de PE}

Para investigar se a série de totais horários de precipitação durante os dias de PE possui características particulares que os distinguem dos demais dias com chuva (particularmente daqueles com totais diários altos mas não-extremos), enfocam-se os dias em que o total diário no CLA é representativo do total no domínio. Inicialmente, para cada dia (24 horas a partir de 12 UTC do dia anterior), com os dados pluviométricos horários da estação meteorológica de superfície do CLA, computam-se o total diário, o número de horas em que o total horário é superior a $0,1,5$, 10 e $20 \mathrm{~mm}$, e o total horário máximo (i.e., maior total 
horário do dia). Limita-se a análise para os meses de março e abril, que é o bimestre com maior número de eventos de $\mathrm{PE}$, e para os dias em que há chuva (total diário $>0 \mathrm{~mm}$ ) tanto no CLA quanto no domínio.

Tercis dos dados de total diário são usados para classificar os dias. As categorias de precipitação baixa (PREC-), normal (PREC0) e alta (PREC + ) contêm os dias que pertencem ao terço inferior, intermediário e superior, respectivamente, de ambos os conjuntos. A categoria PREC+ é dividida em duas: PREC++, que contém os dias de precipitação alta e extrema, e PREC +0 , que contém os dias restantes. A definição das categorias e o número de dias em cada uma delas estão mostrados na Tabela 1. Em cada categoria, pode-se considerar que o total diário no CLA representa o do domínio, pois o procedimento de agrupamento procura excluir os dias em que os sistemas de precipitação afetam partes do domínio, mas não diretamente o CLA.

A categoria PREC++ representa os dias de PE. Para os dias dessa categoria, embora a evolução horária da precipitação difira bastante de um dia para outro (não mostrado), aspectos comuns podem ser encontrados. Uma análise subjetiva sugere que os dias dessa categoria caracterizam-se pela ocorrência de um alto número de horas com chuva e presença de totais horários elevados.

Quanto maior o total diário (ou seja, considerando a sequência PREC-, PREC0 e PREC+), maior é o número de horas com chuva, independentemente do limiar (Fig. 10a), maior é o total horário máximo (Fig. 11), e existe uma clara separação entre as categorias. Em tese, o aumento do total diário pode se dar por duas vias distintas: a primeira é o aumento dos totais horários; a segunda, do número de horas com chuva. Os resultados mostram que não há preferência por uma via específica. Por exemplo, da categoria PREC0 para PREC+, o aumento do total diário resulta tanto do maior número de horas com chuva (de 5 para 10 h) quanto do aumento dos totais horários (maior número de horas com chuvas mais intensas e total horário máximo de 5 para $\left.16 \mathrm{~mm} \mathrm{~h}^{-1}\right)$.

Na categoria PREC-, o pequeno número de horas com chuva $(2 \mathrm{~h})$ e o baixo total horário máximo $\left(<1 \mathrm{~mm} \mathrm{~h}^{-1}\right)$ concordam com as características da maior parte dos eventos de chuva que ocorrem no CLA no trimestre chuvoso (MAM). De acordo com Barros (2008), esses eventos são frequentes (ocorrem cerca de 2 vezes ao dia), e possuem duração curta $(\leq 1 \mathrm{~h})$ e baixo total horário máximo $\left(\leq 0,5 \mathrm{~mm} \mathrm{~h}^{-1}\right)$.

As características da categoria $\mathrm{PREC}+0$ são semelhantes às da categoria PREC+ (Fig. 10b), pois os dias de PREC +0 correspondem a quase $90 \%$ dos dias de PREC + . A categoria PREC++, ao contrário, possui características claramente distintas. Por exemplo, nos dias de PREC++, há mais de $14 \mathrm{~h}$ de chuva (o que é bem superior ao valor de $9 \mathrm{~h}$ de chuva nos dias de PREC+0), quase o dobro do número de horas com chuvas mais intensas em comparação com os dias de PREC +0 , e total horário máximo superior a $20 \mathrm{~mm} \mathrm{~h}^{-1}$ (quase $8 \mathrm{~mm} \mathrm{~h}^{-1}$ superior ao valor de PREC +0 ; Fig. 11). Logo, os dias de PE (incluídos na categoria PREC++) constituem-se em um grupo com características bem distintas em relação aos demais dias de precipitação alta (incluídos na PREC+0).

\section{Considerações finais}

Neste trabalho, abordaram-se os eventos de PE para a região do CLA. Totais diários de precipitação para o período de set-1984 a ago-2014 (30 anos) foram utilizados para identificar os eventos de $\mathrm{PE}$ em um domínio de $1^{\circ} \times 1^{\circ}$ aproximadamente centrado no CLA. Adotando o $99^{\circ}$ percentil da precipitação diária $\left(44 \mathrm{~mm} \mathrm{~d}^{-1}\right)$ como limiar de PE, foram identificados 104 eventos no período.

$\mathrm{O}$ ciclo anual da frequência de eventos de PE e o das excedências foi muito semelhante ao da precipitação. Sazonalmente, houve máximo (mínimo) no trimestre MAM (SON). Como não ocorreram eventos de agosto a outubro,

Tabela 1 - Nome, definição e número de dias das categorias de precipitação.

\begin{tabular}{lcc}
\hline Categoria de precipitação & Definição & Número de dias \\
\hline baixa & total diário no domínio $>0,0 \mathrm{e}<7,5 \mathrm{~mm} \mathrm{e}$ & 159 \\
(PREC-) & total diário no CLA $>0,0 \mathrm{e}<4,0 \mathrm{~mm}$ \\
normal & total diário no domínio $\geq 7,5 \mathrm{e}<17,6 \mathrm{~mm} \mathrm{e}$ & 109 \\
(PREC0) & total diário no CLA $\geq 4,0 \mathrm{e}<15,7 \mathrm{~mm}$ & 164 \\
alta & total diário no domínio $\geq 17,6 \mathrm{~mm} \mathrm{e}$ & 147 \\
(PREC+) & total diário no CLA $\geq 15,7 \mathrm{~mm}$ & \\
alta e não-extrema & total diário no domínio $\geq 17,6 \mathrm{e}<44,0 \mathrm{~mm} \mathrm{e}$ & 17 \\
(PREC+0) & total diário no CLA $\geq 15,7 \mathrm{e}<44,0 \mathrm{~mm}$ \\
alta e extrema & total diário no domínio $\geq 44,0 \mathrm{~mm} \mathrm{e}$ & \\
(PREC++) & total diário no CLA $\geq 44,0 \mathrm{~mm}$ & \\
\hline
\end{tabular}



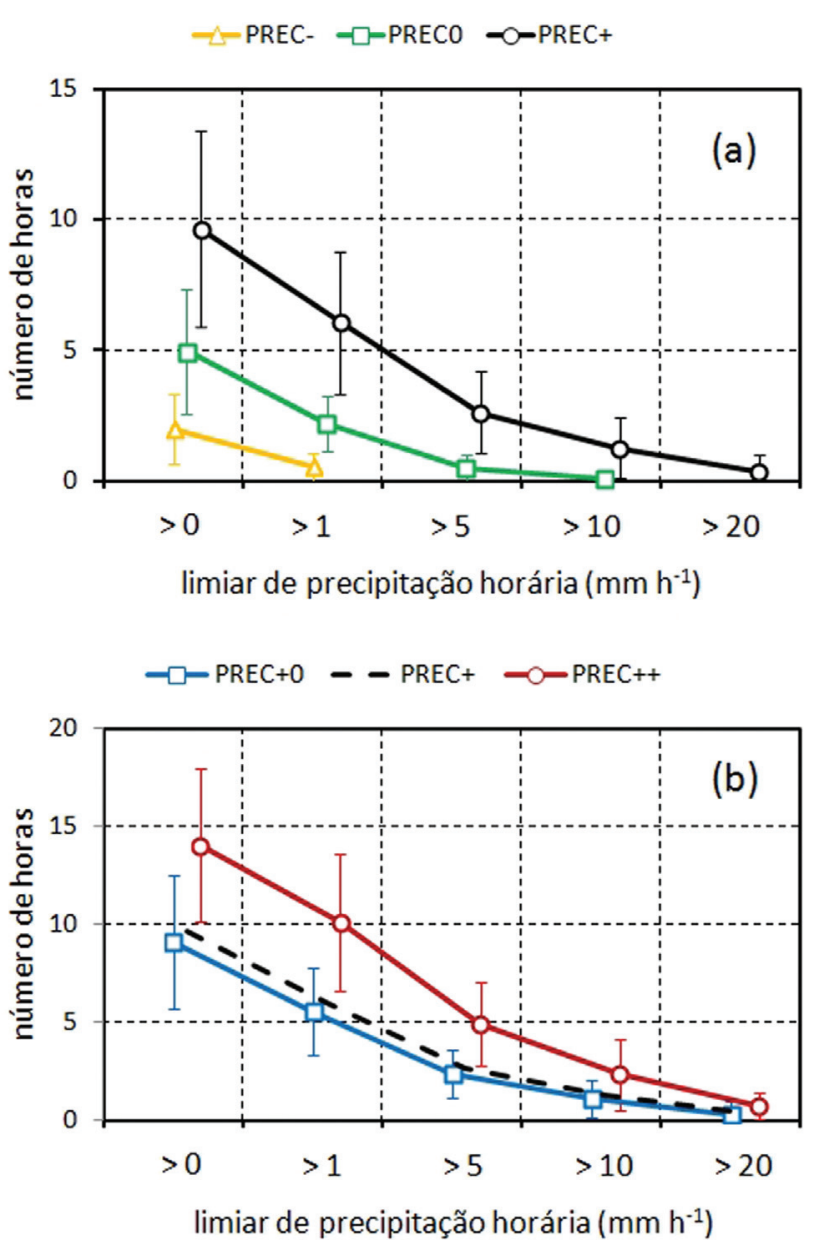

Figura 10 - Média do número de horas do dia em que a precipitação horária é superior a um limiar $\left(0,1,5,10 \mathrm{e} 20 \mathrm{~mm} \mathrm{~h}^{-1}\right)$ para as categorias PREC- (amarelo), PREC0 (verde) e PREC+ (preto) (a); e PREC+0 (azul) e PREC++ (vermelho) (b). As barras representam o desvio padrão. Todas as categorias contêm somente dias com chuva (total diário $>0 \mathrm{~mm}$ ) e estão definidas na Tabela 1. A linha referente à categoria PREC+é repetida no painel "b".

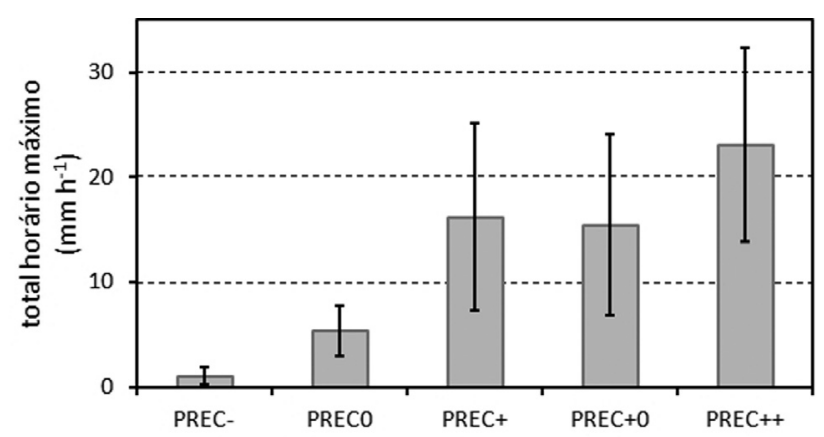

Figura 11 - Média do total horário máximo $\left(\mathrm{mm} \mathrm{h}^{-1}\right)$ para as categorias PREC-, PREC0, PREC+, PREC+0 e PREC++. As barras representam o desvio padrão. Todas as categorias contêm somente dias com chuva (total diário $>0 \mathrm{~mm}$ ) e estão definidas na Tabela 1. definiu-se ano hidrológico como o período de 12 meses a partir de setembro.

Utilizando as séries de duração parcial, os máximos anuais de total diário puderam ser modelados estatisticamente como uma distribuição de Gumbel com parâmetro de escala (posição) de 12,11 mm (58,94 mm). Logo, a precipitação de 1 dia com tempo de retorno de 100 anos seria de $115 \mathrm{~mm}$. Esse valor deve ser tomado com cautela, pois é inferior aos encontrados na literatura para localidades pertencentes ao domínio.

Para o bimestre de março e abril, que concentrou o maior número de eventos, a variabilidade interanual da frequência de eventos esteve correlacionada positiva e significativamente $(R=+0,44)$ com a do total de precipitação. A correlação parcial com outros fatores, como o índice Niño 3, o gradiente inter-hemisférico de TSM do Atlântico e o vento em $925 \mathrm{hPa}$ sobre a região do CLA, não foi significativa. Os dias de PE no bimestre diferenciaram-se dos demais com totais elevados por apresentarem maior número de horas do dia com chuva $(14 \pm 4 \mathrm{~h}) \mathrm{e}$ maiores totais horários (p. ex., total horário máximo $=23 \pm 9 \mathrm{~mm} \mathrm{~h}^{-1}$ ).

No bimestre de março e abril de um ano específico, 1996, ocorreu a maior frequência de eventos (5 eventos). Nesse bimestre, os dias de PE caracterizaram-se pela ocorrência de atividade convectiva intensa sobre duas grandes áreas: uma zonalmente alongada cobrindo a costa norte do Brasil, e outra cobrindo os Estados de Santa Catarina e Paraná.

Os resultados obtidos no presente trabalho sugerem que os eventos de PE na região do CLA poderiam ser descritos da seguinte forma. Sobre uma área ampla cobrindo costa norte do Brasil, possivelmente em resposta a condições atmosféricas muito favoráveis à ocorrência de convecção profunda, iniciar-se-iam sistemas convectivos em diferentes horários. Esses sistemas se desenvolveriam como tempestades multicelulares, levando a uma nebulosidade extensa, espacialmente contínua, persistente e incluindo núcleos convectivos. Sobre a região do CLA, a passagem da parte convectiva dos sistemas levaria ao aumento dos totais horários; da parte estratiforme, ao aumento do número de horas do dia com chuva. Os aspectos dinâmicos e termodinâmicos associados a esse descrição poderão ser abordados em trabalhos futuros utilizando dados de Reanálise e TSM, de forma análoga ao realizado em vários estudos (p. ex., Silva et al., 2009). Os compostos poderiam ser obtidos não somente para os dias de $\mathrm{PE}$, mas também para o dia anterior e posterior ao de PE. Em relação aos dados de Reanálise, como erros sistemáticos expressivos na precipitação são encontrados para a costa norte do Brasil (Vasques et al., 2009), algum procedimento de seleção de dias de PE precisaria ser adotado antes da obtenção dos compostos. 


\section{Agradecimentos}

Parte do trabalho foi realizado no período de ago-2013 a jul-2014, quando o segundo autor (GMO) foi bolsista de iniciação científica do CNPq (PIBIC-IAE) sob orientação do primeiro autor (MDO). Os autores agradecem ao Setor de Meteorologia do CLA e ao Sr. Antonio Luis Cardoso Neto a disponibilização dos dados da estação meteorológica, e aos órgãos da NOAA (EUA) a disponibilização dos conjuntos de dados em grade regular.

\section{Referências}

AHMAD, I.; TANG, D.; WANG, T.; WANG, M.; WAGAN, B. Precipitation trends over time using Mann-Kendall and Spearman's rho tests in Swat River Basin, Pakistan. Advances in Meteorology, v. 2015, ID 431860, 2015.

ANDRADE, M.M.; LIMA, K.C. Projeção climática da frequência de eventos de precipitação intensa no Nordeste do Brasil: resultados preliminares. Revista Brasileira de Geografia Física, v. 6, n. 5, p. 1158-1173, 2013.

ANDREOLI, R.V.; KAYANO, M.T. A importância relativa do Atlântico Tropical Sul e Pacífico Leste na variabilidade de precipitação do Nordeste do Brasil. Revista Brasileira de Meteorologia, v. 22, n. 1, p. 63-74, 2007.

ANDREOLI, R.V.; KAYANO, M.T.; GUEDES, R.L.; OYAMA, M.D.; ALVES, M.A.S. A influência da temperatura da superfície do mar dos Oceanos Pacífico e Atlântico na variabilidade de precipitação em Fortaleza. Revista Brasileira de Meteorologia, v. 19, n. 3, p. 337-344, 2004.

BARROS, S.S. Precipitação no Centro de Lançamento de Alcântara: aspectos observacionais e de modelagem. 102 f. Dissertação (Mestrado em Meteorologia) - Instituto Nacional de Pesquisas Espaciais, São José dos Campos, 2008.

COSTA, J.; MONGIN, J.; BRITO, A.J. Equações de chuvas intensas para São Luís - MA. In: Simpósio Brasileiro de Recursos Hídricos, 17., 2007, São Paulo. Anais... 2007.

COSTA NETO, P.L.O. Estatística. São Paulo: Edgard Blücher, 1977. $264 \mathrm{p}$.

DAYAN, U.; NISSEN, K.M.; ULBRICH, U. Atmospheric conditions inducing extreme precipitation over the Eastern and Western Mediterranean. Natural Hazards and Earth System Sciences Discussions, v. 3, n. 6, p. 3687-3732, 2015.

EASTERLING, D.R.; EVANS, J.L.; GROISMAN, P.Y.; KARL, T.R.; KUNKEL, K.E. et al. Observed variability and trends in extreme climate events: a brief review. Bulletin of the American Meteorological Society, v. 81, n. 3, p. 417-425, 2000.

FARIAS, R.F.L.; ALVES, K.M.A.S.; NÓBREGA, R.S. Climatologia de ocorrência de eventos extremos de precipitação na mesorregião do Sertão Pernambucano. Revista Geonorte, Edição Especial 2, v. 1, n. 5, p. 930-941, 2012.

FERREIRA, N.S.; REPELLI, C.A.; ALVES, J.M.B.; SOUZA, E.B. LOCZCIT - Um procedimento numérico para localização do eixo central da Zona de Convergência Intertropical no Atlântico Tropical. Revista Brasileira de Meteorologia, v. 20, n. 2, p. 159-164, 2005.

GONÇALVES, L.S. Relações intensidade-duração-frequência com base em estimativas de precipitação por satélite. 117 f. Dissertação (Mestrado em Recursos Hídricos e Sanea- mento Ambiental) - Universidade Federal do Rio Grande do Sul, Porto Alegre, 2011.

GRIMM, A.M.; TEDESCHI, R.G. ENSO and extreme rainfall events in South America. Journal of Climate, v. 22, p. 1589-1609, 2009.

GRIMM, A.M. Clima da Região Sul do Brasil. In: CAVALCANTI, I.F.A.; FERREIRA, N.J.; SILVA, M.G.A.J.; SILVA DIAS, M.A.F. (Eds.). Tempo e Clima no Brasil. São Paulo: Ed. Oficina de Textos, 2009, p. 259-275.

INSTITUTO NACIONAL DE METEOROLOGIA. Boletim Agroclimatológico Mensal. v. 48, n. 5, 2014.

KALNAY, E.; KANAMITSU, M.; KISTLER, R.; COLLINS, W.; DEAVEN, D. et al. The NCEP/NCAR 40-Year Reanalysis Project. Bulletin of the American Meteorological Society, v. 77, n. 3, p. 437-471, 1996.

KISTLER, R.; KALNAY, E.; COLLINS, W.; SAHA, S.; WHITE, G. et al. The NCEP-NCAR 50-year reanalysis: monthly means CDROM and documentation. Bulletin of the American Meteorological Society, v. 82, n. 2, p. 247-267, 2001.

LIEBMANN, B. Description of a complete (interpolated) outgoing longwave radiation dataset. Bulletin of the American Meteorological Society, v. 77, n. 6, p. 1275-1277, 1996.

MARQUES, R.F.C.; FISCH, G.F. As atividades de Meteorologia Aeroespacial no Centro Técnico Aeroespacial (CTA). Boletim da Sociedade Brasileira de Meteorologia, v. 29, n. 3, p. 21-25, 2005.

MELO, A.B.C.; CAVALCANTI, I.F.A.; SOUZA, P.P. Zona de Convergência Intertropical do Atlântico. In: CAVALCANTI, I.F.A.; FERREIRA, N.J.; SILVA, M.G.A.J.; SILVA DIAS, M.A.F. (Eds.). Tempo e Clima no Brasil. São Paulo: Ed. Oficina de Textos, 2009, p. 25-41.

NAGHETTINI, M.; PINTO, E.J.A. Hidrologia Estatística. CPRM - Serviço Geológico do Brasil, 2007. 561 p.

OLIVEIRA, P.T. Estudo estatístico sobre eventos de precipitação intensa no Nordeste do Brasil. 98 f. Tese (Doutorado em Ciências Climáticas) - Universidade Federal do Rio Grande do Norte, Natal, 2014a.

OLIVEIRA, G.M. Eventos extremos de precipitação na região do Centro de Lançamento de Alcântara. Relatório final de bolsa de iniciação científica (PIBIC-CNPq-IAE). Instituto de Aeronáutica e Espaço, 2014b. 9 p.

OLIVEIRA, F.P.; Oyama, M.D. Antecedent atmospheric conditions related to squall-line initiation over the Northern Coast of Brazil in July. Weather and Forecasting, v. 30, p. 1254-1264, 2015.

PEREIRA, E.I.; MIRANDA, I.; FISCH, G.F.; MACHADO, L.A.T.; ALVES, M.A.S. Atlas climatológico do Centro de Lançamento de Alcântara. São José dos Campos: Centro Técnico Aeroespacial, 2002. (ACA/RT-01/01, GDO-000000/B0047)

PINHEIRO, U.A.; OYAMA, M.D. Rainy Season Features for the Alcântara Launch Center. Journal of Aerospace Technology and Management, v. 5, n. 4, p. 439-448, 2013.

SANSIGOLO, C.A. Distribuições de Extremos de Precipitação Diária, Temperatura Máxima e Mínima e Velocidade do Vento em Piracicaba, SP (1917-2006). Revista Brasileira de Meteorologia, v. 23, n. 3, p. 341-346, 2008.

SMITH, T.M.; REYNOLDS, R.W.; PETERSON, T.C.; LAWRIMORE, J. Improvements to NOAA's historical merged land-ocean surface temperature analysis 
(1880-2006). Journal of Climate, v. 21, n. 10, p. 2283-2296, 2008.

SILVA, G.A.M.; AMBRIZZI, T.; MARENGO, J.A. Observational evidences on the modulation of the South American Low Level Jet east of the Andes according the ENSO variability Annales Geophysicae, v. 27, p. 645-657, 2009.

SOUSA, S.B. Equações de Chuva para 30 Localidades Maranhenses. In: Simpósio Brasileiro de Recursos Hídricos, 17. 2007, São Paulo. Anais... 2007.

TANK, A.M.G.K.; ZWIERS, F.W.; ZHANG, X. Guidelines on "Analysis of extremes in a changing climate in support of informed decisions for adaptation". World Meteorological Organization: Climate Data and Monitoring, WCDMP-No. 72. 2009. 52 p.

TOMASSINI, L.; JACOB, D. Spatial analysis of trends in extreme precipitation events in high-resolution climate model results and observations for Germany. Journal of Geophysical Research, v. 114, D12113, 2009.

TORRES, R.R.; FERREIRA, N.J. Case studies of easterly wave disturbances over Northeast Brazil using the Eta model. Weather and Forecasting, v. 26, p. 225-235, 2011.
VASQUES, A.C.; FRANCHITO, S.H.; RAO, V.B.; SANTO, C.M.E.; CONFORTE, J.C. Comparação entre diferentes fontes de dados de precipitação sobre a América do Sul com ênfase no Brasil. Boletim da Sociedade Brasileira de Meteorologia, v. 33, n. 1, p. 5-16, 2009.

VIEIRA, V.R. Regionalização e riscos de índices de chuvas intensas no Nordeste do Brasil. 121 f. Dissertação (Mestrado em Meteorologia) - Universidade Federal de Campina Grande, Campinha Grande, 2014.

VILLARINI, G.; SMITH, J.A.; NTELEKOS, A.A.; SCHWARZ, U. Annual maximum and peaks-over-threshold analyses of daily rainfall accumulations for Austria. Journal of Geophysical Research, v. 116, D05103, 2011.

XIE, P.; CHEN, M.; YANG, S.; YATAGAI, A.; HAYASAKA, T. et al. A gauge-based analysis of daily precipitation over East Asia. Journal of Hydrometeorology, v. 8, n. 3, p. 607-626, 2007.

YIOU, P.; GOUBANOVA, K.; LI, Z.X.; NOGAJ, M. Weather regime dependence of extreme value statistics for summer temperature and precipitation. Nonlinear Processes in Geophysics, v. 15, p. 365-378, 2008.

This is an Open Access article distributed under the terms of the Creative Commons Attribution Non-Commercial License which permits unrestricted non-commercial use, distribution, and reproduction in any medium provided the original work is properly cited. 